\section{Rheumatoid cervical joint disease - a challenge to the anaesthetist}

Alison Macarthur MD, Simcha Kleiman MD
Cervical joint disease in rheumatoid arthritis patients is common. These patients may be at risk for severe life-threatening neurological problems in the perioperative period and thus present $a$ challenge to the anaesthetist. By understanding the various anatomical abnormalities that may occur in rheumatoid cervical joint disease, the anaesthetist can design an appropriate management plan for the patient. The destruction of normal anatomy by rheumatoid arthritis can result in atlanto-axial subluxation (AAS) or subaxial subluxation. The atlanto-axial subluxation is further divided anatomically into anterior $A A S$, posterior $A A S$, vertical $A A S$, and lateral/rotatory $A A S$. In addition to the history and physical examination of the rheumatoid arthritis patient, radiological evaluation of the cervical spine is highly recommended. With the identification of the specific anatomical lesion the anaesthetist can predict and avoid movements which may lead to, or worsen, neurological problems. In the event of an emergency where full evaluation of the cervical spine is not possible the anaesthetist must presume that the rheumatoid patient has severe cervical spine instability and use the most cautious approach.

On rencontre souvent une atteinte de la colonne cervicale dans l'arthrite rhumatoïde. A la période périopératoire, ceux qui en souffrent présentent un risque élevé de complications neurologiques gravissimes et par le fait même un défi pour l'anesthésie. C'est par la compréhension des anomalies anatomiques variées qui surviennent au cours de la maladie que l'anesthésiste peut développer un plan de conduite appropriée pour ces patients. La destruction de l'anatomie normale par l'arthrite rhumatoide peut causer une subluxation de l'articulation atloïdo-

\section{Key words}

COMPLICATIONS: rheumatoid arthritis; INTUBATION, TRACHEAL: complications.

From the Department of Anaesthesia, SMBD - Jewish General Hospital, and McGill University, Montreal, Quebec.

Address correspondence to: Dr. S. Kleiman, Department of Anaesthesia, Room A-335, SMBD - Jewish General Hospital, 3755 Cote Ste, Catherine Road, Montreal, Quebec, H3T 1E2.

Accepted for publication 10th October 1992. axoïdienne ou sous-axoïdienne. La subluxation atloïdienne se subdivise anatomiquement en antérieure, postérieure, verticale et latéro-rotatoire. En plus de l' istoire et l'examen physique de l'arthritique, une évaluation radiologique de la colonne cervicale est fortement recommandée. Grâce à lidentification des lésions anatomiques spécifiques, l'anesthésiste peut prévenir et éviter des mouvements susceptibles d'entraîner et d'aggraver les complications neurologiques. Dans léventualité d'une situation d'urgence ne permettant pas d'évaluation complète, lanesthésiste doit toujours présumer que le patient rhumatoïde souffre d'une instabilité du rachis cervical grave et agir avec extrême prudence.

Patients with rheumatoid cervical joint disease (RCJD) may be at risk for severe life-threatening neurological problems in the perioperative period. The challenge to the anaesthetist is in understanding the various anatomical abnormalities of the rheumatoid cervical spine. This allows the anaesthetist to design an appropriate management approach to these patients.

\section{Demographics}

The prevalence of rheumatoid arthritis (RA) in the USA is estimated to be between $0.3-1.5 \%{ }^{1}$ The disease is autoimmune in nature, and any of the body's synovial joints may be affected. Cervical joint involvement has been reported in different series to affect between $15-86 \%$ of patients with RA. ${ }^{2-5}$ Higher incidence of cervical joint involvement in RA patients occurs in those who are seropositive for rheumatoid factor, those with severe erosive disease of peripheral joints, and in patients on longterm steroid therapy. $2,5,6$ Whereas RA has a female to male predilection of 2-3:1, cervical joint involvement appears to be more common in males. Patients with juvenile RA do not appear to be at risk of developing RCJD. ${ }^{7}$

\section{Anatomy}

The normal organization of the cervical spine allows a high degree of mobility without damage to the contents of the neck. This complex integration of vertebral bodies, facet joints, synovial capsules and ligaments can be se- 


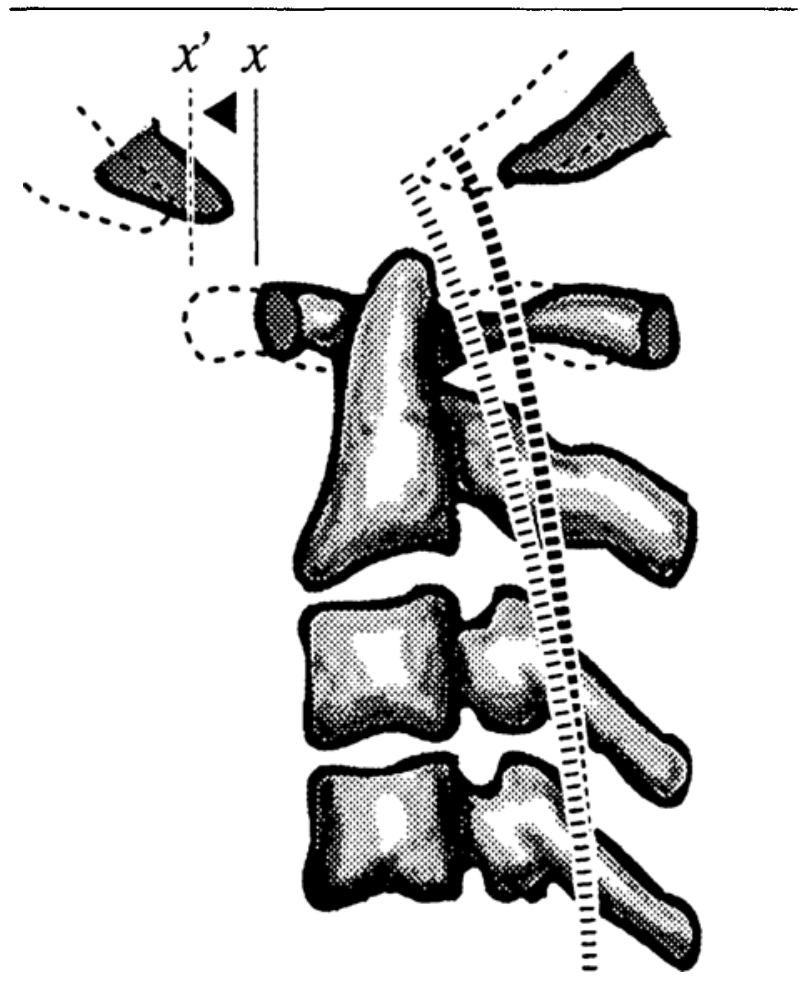

FIGURE I Types of atlanto-axial subluxation (AAS): $(x=$ normal position of anatomical reference; $x^{\prime}=$ pathological position after subluxation; $=$ normal position of spinal cord). Anterior $A A S-$ Lateral view of cranium and upper cervical spine. $C_{1}$ moves forward relative to $\mathrm{C}_{2}$ due to transverse ligament destruction. (Dotted outline of $C_{1}$ and cranium represent their direction of movement with anterior AAS; $\bar{\equiv}=$ forward traction of spinal cord by cranial contents with anterior AAS.)

verely disrupted by RA, leading initially to cervical spine subluxation which is followed occasionally by ankylosis of the cervical spine. The resulting cervical pathology has been divided into two main categories based on the anatomical abnormality: atlanto-axial subluxation (AAS) and subaxial subluxation. Atlanto-axial subluxation can be further defined by the particular direction that the atlas $\left(C_{1}\right)$ subluxes in relation to the axis $\left(C_{2}\right)$ : anterior AAS, posterior AAS, vertical AAS, and lateral/rotatory AAS. ${ }^{6}$

\section{Atlanto-axial subluxation}

The $\mathrm{C}_{1} \mathrm{C}_{2}$ vertebrae, interposing discs, ligaments and joints are the areas most commonly affected by RA of the cervical spine (15-35\% of RA patients). ${ }^{3}$ Depending upon the particular supporting element which is destroyed, the atlas may sublux in relation to the axis in one of the four above-mentioned directions.

1 Anterior AAS $-C_{1}$ moves forward on $C_{2}$ due to trans-

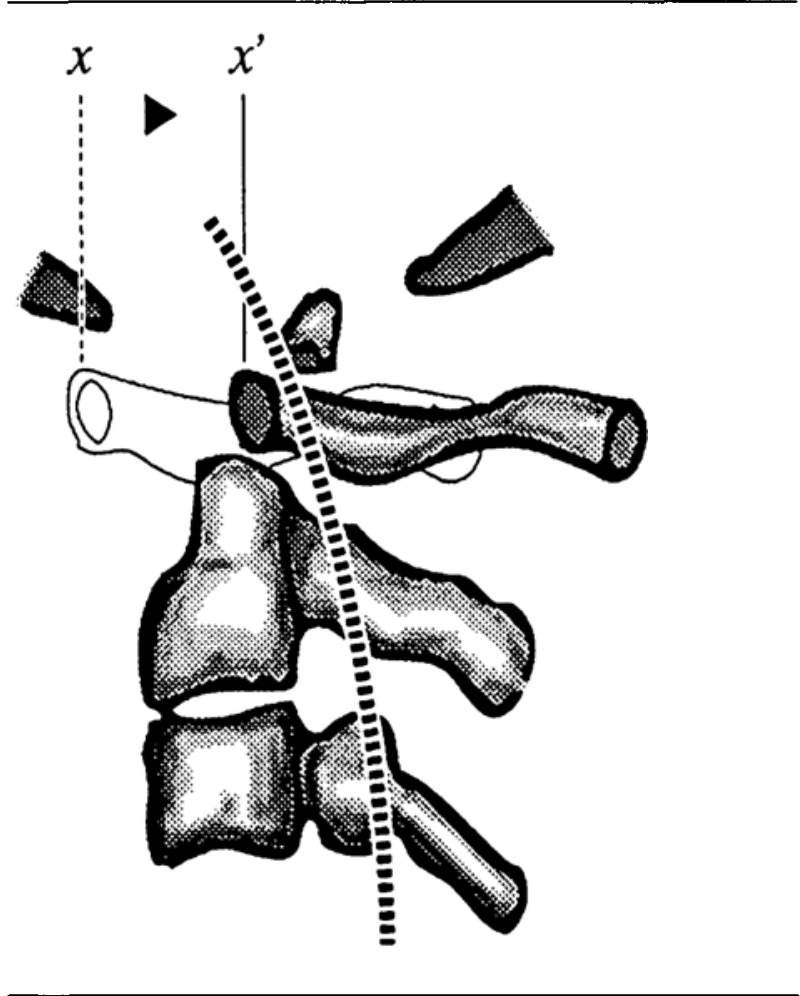

FIGURE 2 Posterior $A A S$ - Lateral view. $\mathrm{C}_{1}$ moves posterior relative to $C_{2}$ due to odontoid process destruction. (Outline of $C_{1}$ represents the normal position; shaded $C_{1}$ and $C_{2}$ represent abnormal position.)

verse ligament destruction ${ }^{4-6}$ (Figure 1). This can result in compression of the cervical cord by the odontoid process. Anterior AAS compromises $80 \%$ of all AAS and is determined radiologically by examining the flexion view of lateral neck $x$-rays. Magnetic resonance imaging has also been reported to be useful in evaluating not only bony destruction and movement but actual neural compression. ${ }^{10,11}$ Subluxation is said to exist when the distance between the atlas and odontoid process in the lateral flexion view exceeds $3 \mathrm{~mm}$ in patients over $44 \mathrm{yr}$ or exceeds $4 \mathrm{~mm}$ in younger patients.

2 Posterior AAS - $C_{1}$ moves backward on $C_{2}$ due to odontoid peg destruction (Figure 2). This is a rare form of AAS accounting for only 3-7\% of patients. This lesion is best demonstrated on lateral extension $x$-rays of the neck.

3 Vertical AAS - Erosive joint diseases in the atlantooccipital/atlanto-axial joints leads to destruction of the lateral masses of $\mathrm{C}_{1}{ }^{3 ., 69}$ The odontoid process may then sublux upwards through the foramen magnum to compress the cervicomedullary junction (Figure 3). The 


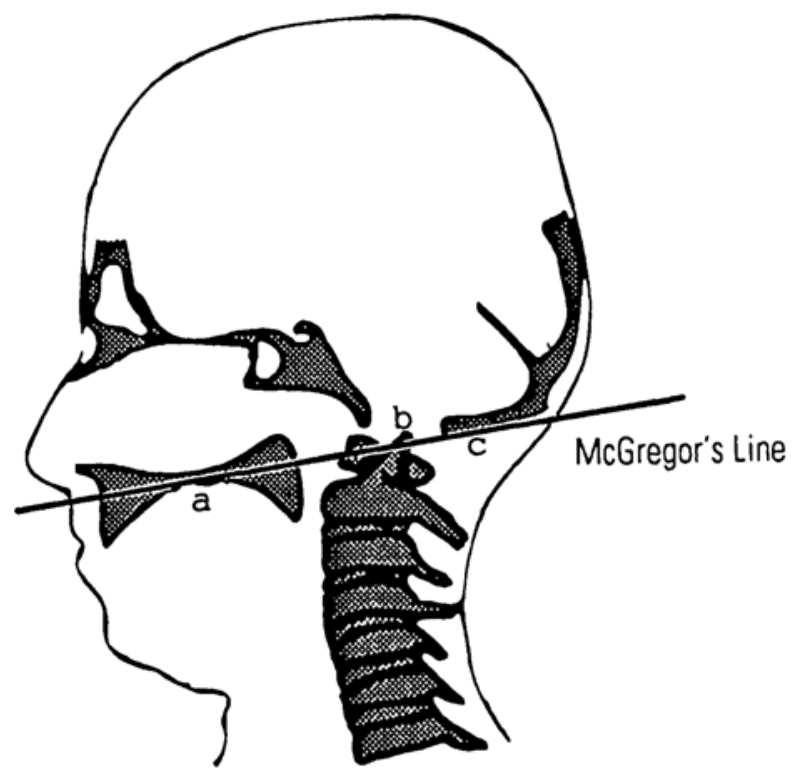

FIGURE 3 Vertical $A A S$ - Lateral view. Destruction of lateral masses of $C_{1}$ allow upward subluxation of the odontoid process through the foramen magnum. ( $a=$ hard palate; $b=$ tip of odontoid process; $\mathrm{c}=$ occipital curve)

prevalence of this type is $10-20 \%$ of all AAS and it may exist in combination with anterior AAS. Radiological evaluation of lateral skull and C-spine $x$-rays, and odontoid views through the mouth reveal that the tip of the odontoid process is superior to MacGregor's line (drawn from the upper surface of the posterior edge of the hard palate to the most caudal point on the occipital curve) by $>8 \mathrm{~mm}$ in men and $>9.5 \mathrm{~mm}$ in women.

4 Lateral/Rotatory AAS - Changes in the $\mathrm{C}_{1} \mathrm{C}_{2}$ facet joints lead to these uncommon deformities. ${ }^{6}$ They occur in approximately $2-5 \%$ of all patients with AAS. Lateral view tomograms of the occiptocervical junction and open mouth views of the odontoid are used to evaluate these deformities. The lateral or rotatory AAS deformities are characterized by $C_{1}$ moving laterally or rotationally with respect to $\mathrm{C}_{2}$ (Figures 4 and 5); they may cause nonreducible rotational head tilt, spinal nerve compression, or vertebral artery compromise.

\section{Subaxial subluxation}

A less common deformity than those of the $C_{1} C_{2}$ region, subaxial subluxations (subluxations below $\mathrm{C}_{2}$ ) occur in $10-20 \%$ of the RA population and appear to correlate with disease duration (as compared to AAS which do

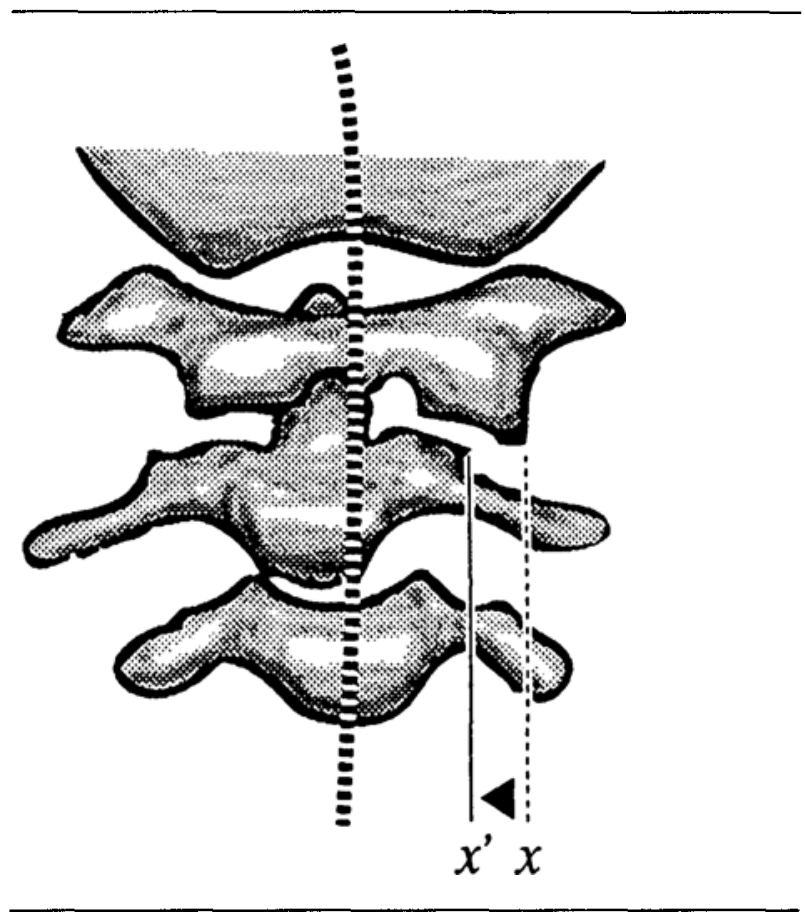

FIGURE 4 Lateral AAS - Posterior view of cranium and upper cervical spine. $C_{1}$ and $C_{2}$ move laterally with respect to one another due to $\mathrm{C}_{1} \mathrm{C}_{2}$ facet destruction.

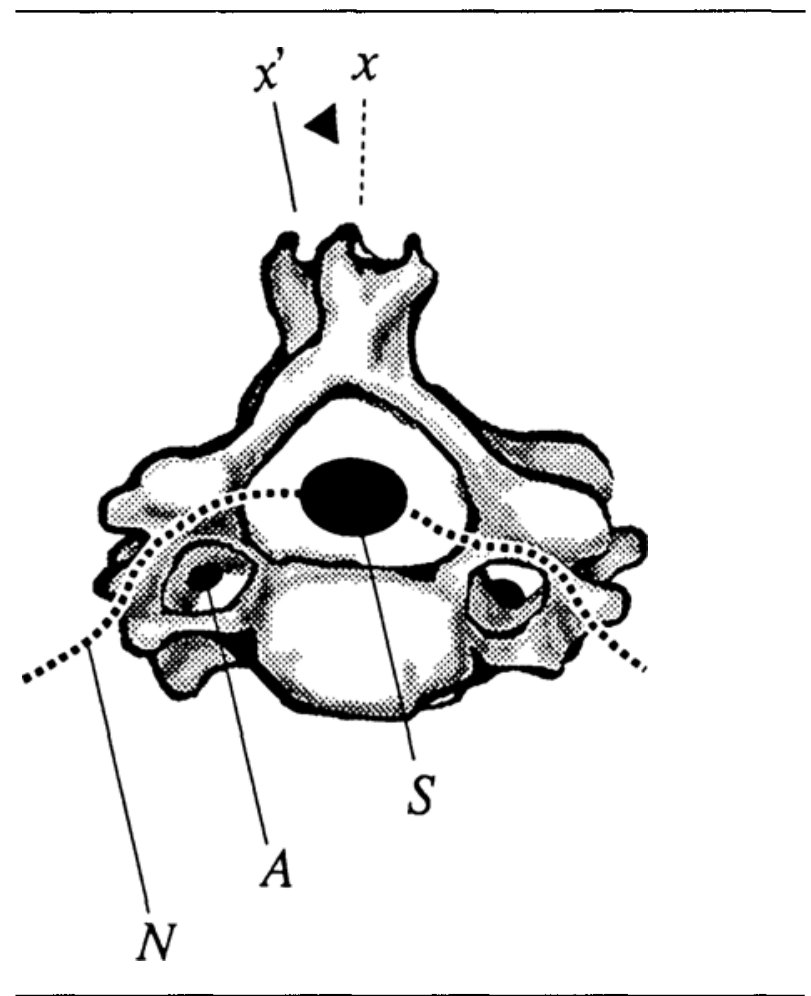

FIGURE 5 Rotatory $A A S-\mathrm{X}$-sectional view of $\mathrm{C}_{1}$ and $\mathrm{C}_{2}$. $\mathrm{C}_{1} \mathrm{C}_{2}$ facet destruction allows rotation of $\mathrm{C}_{1}$ on $\mathrm{C}_{2}$ with resulting compression of spinal nerve $(\mathrm{N})$, vertebral artery $(\mathrm{A})$, or spinal cond (S). 


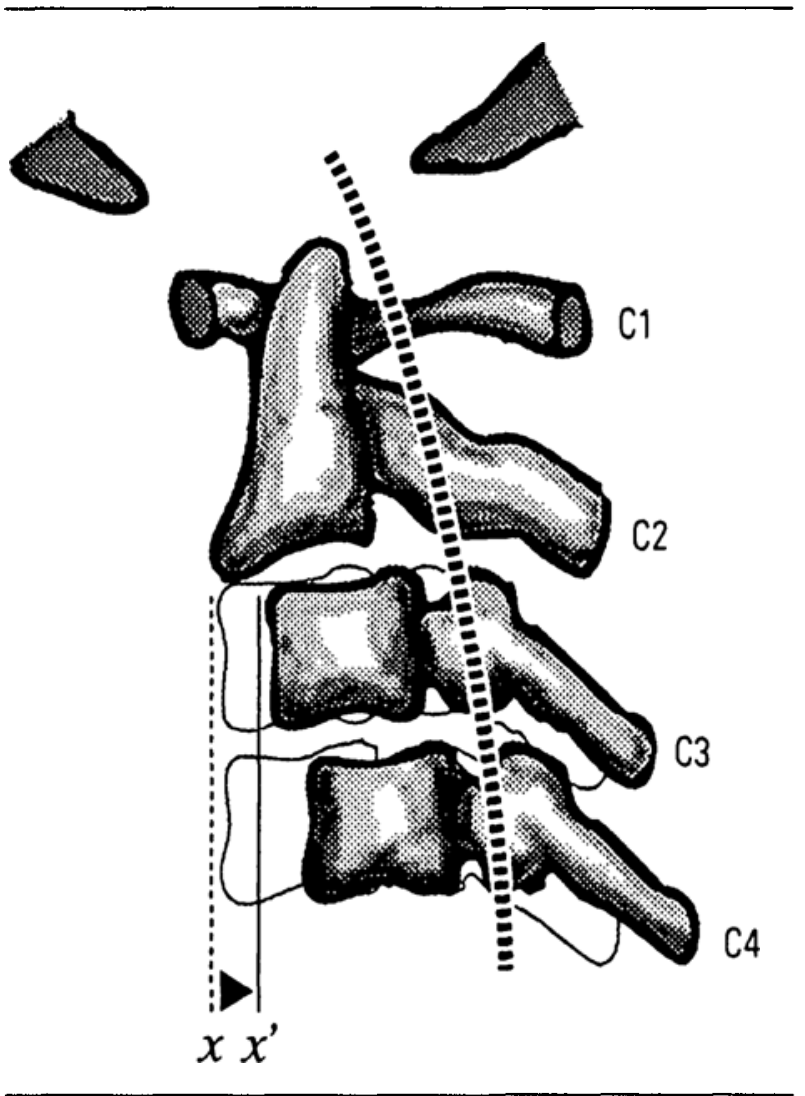

FIGURE 6 Subaxial subluxation: $(x=$ normal position of anatomical reference; $x^{\prime}=$ pathological position after subluxation; $=$ normal position of spinal cond; outline of $C_{1}$ and $C_{2}$ represent their normal anatomical position; shaded drawings of $C_{1}$ and $C_{2}$ represent their position after subluxation). Destruction of facet joints below the level of $C_{2}$ allows antero-posterior subluxation of the vertebral bodies.

not correlate with disease duration). ${ }^{4,6}$ Compared with subluxation at the atlanto-axial level, subaxial subluxation with its pathological change of facet joint destruction can lead to earlier cervical column and spinal nerve compression because of the smaller diameter at these lower levels. The commonest level of involvement is $\mathrm{C}_{5} \mathrm{C}_{6}$ but more than one level may be involved. Lateral views of the cervical spine reveal a step deformity $>2 \mathrm{~mm}$ (Figure 6).

While synovial joint destruction initially leads to subluxation, it is important to bear in mind that cervical spine ankylosis may develop as a final pathological state of rheumatoid arthritis. This ankylosis may result in a flexion deformity of the neck. ${ }^{12,13}$

\section{Evaluation and anaesthetic management}

Patients with RCJD may present for surgical repair of their neck pathology, or for unrelated surgery. Those with poor neck mobility may present difficulty in visualization of the larynx. Other patients may be at risk of neuro- logical and/or vascular damage resulting from cervical subluxation during laryngoscopy or neck positioning perioperatively. Deaths have been reported related to manipulation of the neck during the perioperative period in these patients. ${ }^{14-16}$ Consequently, in addition to the assessment of other medical problems of RA, it is important that the anaesthetist evaluate the cervical spine for RCJD.

Patients with RCJD may present with a puzzling array of symptoms and clinical findings. Disruption of the normal vertebral anatomy may cause vertebral artery compression, as well as compression of the cervical cord or spinal nerves. Patients may complain of occipital headaches (due to entrapment of the $\mathrm{C}_{1} \mathrm{C}_{2}$ roots); dysphagia, dysphonia, diplopia (due to cranial nerve compression with vertical AAS); persistent pain in the neck and arms (due to radicular entrapment at the subaxial level); involuntary movements of the extremities, attacks of dizziness and numbness in the upper extremities (due to long tract compression or vertebral artery insufficiency).

Physical assessment of these patients may be difficult due to the joint and muscle abnormalities associated with chronic RA. Long tract signs, spastic tetraparesis or paraparesis are suggestive of RCJD.

The usual preoperative physical examination with demonstration of neck flexion and atlanto-occipital extension to predict ease of laryngoscopy must be conducted gently, especially in those patients complaining of symptoms exacerbated by neck movement. ${ }^{12,17,18}$ Thorough assessment is required because both non-reducible and rotational subluxations and the later development of cervical ankylosis of RA may greatly interfere with neck mobility making laryngoscopy difficult.

Since cervical involvement in the adult form of RA is common (15-86\%) and may be present in the absence of signs or symptoms, ${ }^{19}$ all adult patients with RA should undergo radiological evaluation before anaesthesia. On the basis of the resulting radiological findings a "lesion specific" approach can be developed to head and neck positioning both for laryngoscopy and for perioperative head positioning (Table). For some surgical procedures regional anaesthesia may be appropriate and may avoid the need for neck manipulation.

\section{Atlanto-axial subluxation}

1 Anterior atlanto-axial subluxation - Anterior AAS is worsened by $C_{1} C_{2}$ flexion. Extension of the $C_{1} C_{2}$ joint by direct laryngoscopy is therefore tolerated. The head should be maintained in a neutral to slightly extended position throughout the perioperative period.

2 Posterior atlanto-axial subluxation - This lesion is wor- 
TABLE

\begin{tabular}{|c|c|c|}
\hline $\begin{array}{l}\text { Rheumatoid C-spine } \\
\text { abnormality }\end{array}$ & $\begin{array}{l}\text { Potential problems for } \\
\text { anaesthetist }\end{array}$ & $\begin{array}{l}\text { Anaesthetist approach to } \\
\text { C-spine }\end{array}$ \\
\hline \multicolumn{3}{|l|}{$\begin{array}{l}\text { Atlanto-axial subluxation } \\
(A A S)\end{array}$} \\
\hline I Anterior AAS & $\begin{array}{l}\mathrm{C}_{1} \mathrm{C}_{2} \text { flexion may cause anterior } \\
\text { spinal cord compression by } \\
\text { odontoid process. }\end{array}$ & $\begin{array}{l}\text { Avoid } \mathrm{C}_{1} \mathrm{C}_{2} \text { flexion during } \\
\text { anaesthesia induction, surgical } \\
\text { positioning or transport. Direct } \\
\text { laryngoscopy is tolerated since } \\
\mathrm{C}_{1} \mathrm{C}_{2} \text { is in extension. }\end{array}$ \\
\hline 2 Posterior AAS & $\begin{array}{l}\mathrm{C}_{1} \mathrm{C}_{2} \text { extension may cause anterior } \\
\text { spinal cord compression by atlas. }\end{array}$ & $\begin{array}{l}\mathrm{C}_{1} \mathrm{C}_{2} \text { extension must be avoided. } \\
\text { Direct larnygoscopy poses a } \\
\text { significant risk - is best avoided. }\end{array}$ \\
\hline 3 Vertical AAS & $\begin{array}{l}\text { Since the odontoid process protrudes } \\
\text { through the foramen magnum, } \\
\text { both flexion and extension may } \\
\text { cause medullary compression. }\end{array}$ & $\begin{array}{l}\text { Neutral head/neck positioning is } \\
\text { mandatory throughout the } \\
\text { perioperative period. Direct } \\
\text { laryngoscopy should be avoided. }\end{array}$ \\
\hline 4 Lateral/rotatory AAS & $\begin{array}{l}\text { Lateral shift or rotation of } \mathrm{C}_{1} \mathrm{C}_{2} \text { may } \\
\text { compress vertebral arteries and/or } \\
\text { spinal nerves. Severe lateral shift } \\
\text { may lead to spinal cord } \\
\text { compression. }\end{array}$ & $\begin{array}{l}\text { Avoid any rotation or lateral } \\
\text { movements of the head during the } \\
\text { perioperative period. } \\
\text { Nonreducible head tilt may } \\
\text { preclude direct laryngoscopy. }\end{array}$ \\
\hline Subaxial subluxation & $\begin{array}{l}\text { Uncontrolled vigorous manipulation } \\
\text { of the head and neck may cause } \\
\text { spinal cord compression. }\end{array}$ & $\begin{array}{l}\text { Direct laryngoscopy with neck } \\
\text { stabilization in a neutral position } \\
\text { should be tolerated. }\end{array}$ \\
\hline
\end{tabular}

sened by $\mathrm{C}_{1} \mathrm{C}_{2}$ extension. Therefore direct laryngoscopy is not recommended. (Refer to recommendations below for vertical AAS.) The head should be maintained in a neutral to slightly flexed position.

3 Vertical atlanto-axial subluxation - Vertical AAS is the most life-threatening of RCJD lesions due to the potential for cervical medullary compression. Throughout the perioperative period, the head and neck should always be maintained in a neutral position. Neutral positioning for the cervical spine can best be achieved utilizing the Philadelphia collar with bilateral sandbags joined by tape across the forehead. Soft collars, extrication collars, hard collars and Philadelphia collars alone are not sufficient to prevent flexion, extension, lateral or rotatory movements. ${ }^{20}$ For airway control direct laryngoscopy, either awake or under anaesthesia, should be avoided. Safer techniques, which rely less on atlanto-axial extension, include awake fibreoptic tracheal intubation, ${ }^{21}$ awake blind nasal intubation, ${ }^{22}$ retrograde intubation, ${ }^{23}$ or awake tracheostomy.

4 Lateral/rotatory atlanto-axial subluxation - These rare lesions will be exacerbated with rotational or lateral head movements and the anaesthetist must be careful in avoiding these directions of movement. The $\mathrm{C}_{1} \mathrm{C}_{2}$ extension during direct laryngoscopy is tolerated as long as the patient does not have problems with this movement preoperatively.

\section{Subaxial subluxation}

This collection of lesions is potentially exacerbated by extreme flexion and extension movements of the lower cervical spine. However, these lesions should not cause great problems since the lower cervical spine is straight at the time of direct laryngoscopy although the larynx is flexed. ${ }^{24}$ Therefore, as with the recommendations for traumatic C-spine injuries which these lesions resemble, direct laryngoscopy with neutral neck stabilization should be tolerated. ${ }^{25}$

Unlike patients with cervical joint subluxation, in whom movement of the head and neck may endanger neurological or vascular elements, the cervical joints of patients with late-stage cervical ankylosis may be fixed with resultant limitation of movement. This should be recognized and evaluated preoperatively in order to plan an appropriate approach to the airway.

In summary, when time allows the careful radiological evaluation of the C-spine, the anaesthetist can utilise a "lesion specific" approach to intubation and head positioning. The perioperative head position which is tolerated by all lesions is the neutral cervical spine. Direct laryn- 
goscopy should be avoided in cases of vertical or posterior AAS. Patients with other RCJD lesions should tolerate direct laryngoscopy.

In the urgent, life-threatening situation in which no time is available to evaluate the cervical spine radiologically before surgery, an approach to intubation must be developed which allows near total immobilization of the head and cervical spine. Since near maximal atlantoaxial extension is required for direct laryngoscopic visualization of the larynx, ${ }^{24}$ the authors recommend avoidance of direct laryngoscopy in these patients. Use of one of the airway techniques previously recommended for vertical atlanto-axial subluxation management is suggested. The authors' preference is for awake flexible fibreoptic tracheal intubation.

\section{Conclusion}

Rheumatoid cervical joint disease is a common manifestation of adult rheumatoid arthritis. In the patient presenting for elective surgery preoperative radiological assessment of the neck is highly recommended. Direct laryngoscopy should be avoided in those RA patients with posterior or vertical atlanto-axial subluxation. In patients with other forms of AAS the trachea may be intubated with the help of direct laryngoscopy with appropriate neck stabilization.

In the case of urgent life-threatening problems where anaesthesia must be administered without complete evaluation of the cervical spine, the anesthetist should treat the rheumatoid patient as though he were at risk of lifethreatening cervical spine instability and use the most cautious approach to airway management.

\section{References}

1 Zvaifler NJ. Etiology and pathogenesis of rheumatoid arthritis. In: McCarty DJ (Ed.). Arthritis and Allied Condition: A Textbook of Rheumatology (11th ed.). Philadelphia, Lea \& Febiger, 1989; 659.

2 Watt I, Cummins B. Management of rheumatoid neck. Ann Rheum Dis 1990; 49: 805-7.

3 Sherk $H H$. Atlanto/axial instability and acquired basilar invagination in rheumatoid arthritis. Orthop Clin North Am 1978; 9: 1053-63.

4 Smith PH, Benn RT, Sharp J. Natural history of rheumatoid cervical luxations. Ann Rheum Dis 1972; 31: 431-9.

5 Bland JH. Rheumatoid subluxation of the cervical spine (editorial). J Rheumatol 1990; 17: 134-7.

6 Santavirta S, Kankaanpää U, Sandelin J, Laasonen E, Konttinen YT, Slätis $P$. Evaluation of patients with rheumatoid cervical spine. Scand J Rheumatol 1987; 16: 9-16.

7 Hensinger RN, De Vito PD, Ragsdale CG. Changes in the cervical spine in juvenile rheumatoid arthritis. $J$ Bone Joint Surg (Am) 1986; 68A: 189-98.
8 Marks JS. Rheumatoid neck. Br J Hosp Med 1985; 33: 96-100.

9 Hancock DO. The cervical spine in chronic rheumatoid arthritis. Clin Rheum Dis 1978; 4: 443-59.

10 Foley-Nolan D, Stack JP, Ryan M, et al. Magnetic resonance imaging in the assessment of rheumatoid arthritis a comparison with plain film radiographs. $\mathrm{Br} \mathrm{J}$ Rheumatol 1991; 30: 101-6.

11 Breedveld FC, Algra PR, Vielvoye CJ, Cats A. Magnetic resonance imaging in the evaluation of patients with rheumatoid arthritis and subluxations of the cervical spine. Arthritis Rheum 1987; 30: 624-9.

12 Edelist $G$. Principles of anesthetic management in rheumatoid arthritic patients. Anesth Analg 1964; 43: 227-31.

13 Eisele JH. Connective tissue diseases. In: Katz J, Benumof J, Kadis LB (Eds.). Anesthesia and Uncommon Diseases. Toronto: WB Saunders, 1981, 510-6.

14 Mikulowski P, Wollheim FA, Rotmil P, Olson I. Sudden death in rheumatoid arthritis with atlanto-axial dislocation. Acta Med Scand 1975; 198: 445-8.

15 Martel W, Page JW. Cervical vertebral erosions and subluxations in rheumatoid arthritis and ankylosing spondylitis. Arthritis Rheum 1960; 3: 546.

16 Munthe $E$. The cervical spine in rheumatoid arthritis (Editorial). Scand J Rheum 1987; 16: 7.

17 Moncur C, Williams HJ. Cervical spine management in patients with rheumatoid arthritis. Phys Ther 1988; 68: 509-15.

18 Santavirta S, Slätis $P$, Kankaanpää U, Sandelin J, Laasonen $E$. Treatment of the cervical spine in rheumatoid arthritis. J Bone Joint Surg (Br) 1988; 70: 658-67.

19 Pellici PM, Ranawat CS, Tsairis P, Bryan WJ. A prospective study of the progression of rheumatoid arthritis of the cervical spine. J Bone Joint Surg (Am) 1981; 63A: 342-50.

20 Podolsky S, Baraff LJ, Simon RR, Hoffman JR, Larmon $B$, Ablon $W$. Efficacy of cervical spine immobilization methods. J Trauma 1983; 23: 461-5.

21 Patil VU, Stehling LC, Zauder HI. Fiberoptic endoscopy in anesthesia. Chicago: Year Book Medical Publishers, 1983; 78-87.

22 Gold MI, Buechel DR. A method of blind nasal intubation for the conscious patient. Anesth Analg 1960; 39: 257-63.

23 Barriot $P$, Riou B. Retrograde technique for tracheal intubation in trauma patients. Crit Care Med 1988; 16: 712-3.

24 Horton WA, Fahy L, Charters P. Disposition of cervical vertebrae, altanto-axial joint, hyoid and mandible during $x$ ray laryngoscopy. Br J Anaesth 1989; 63: 435-8.

25 Hastings $R H$, Marks $J D$. Airway management for trauma patients with potential cervical spine injuries. Anesth Analg 1991; 73: 471-82. 